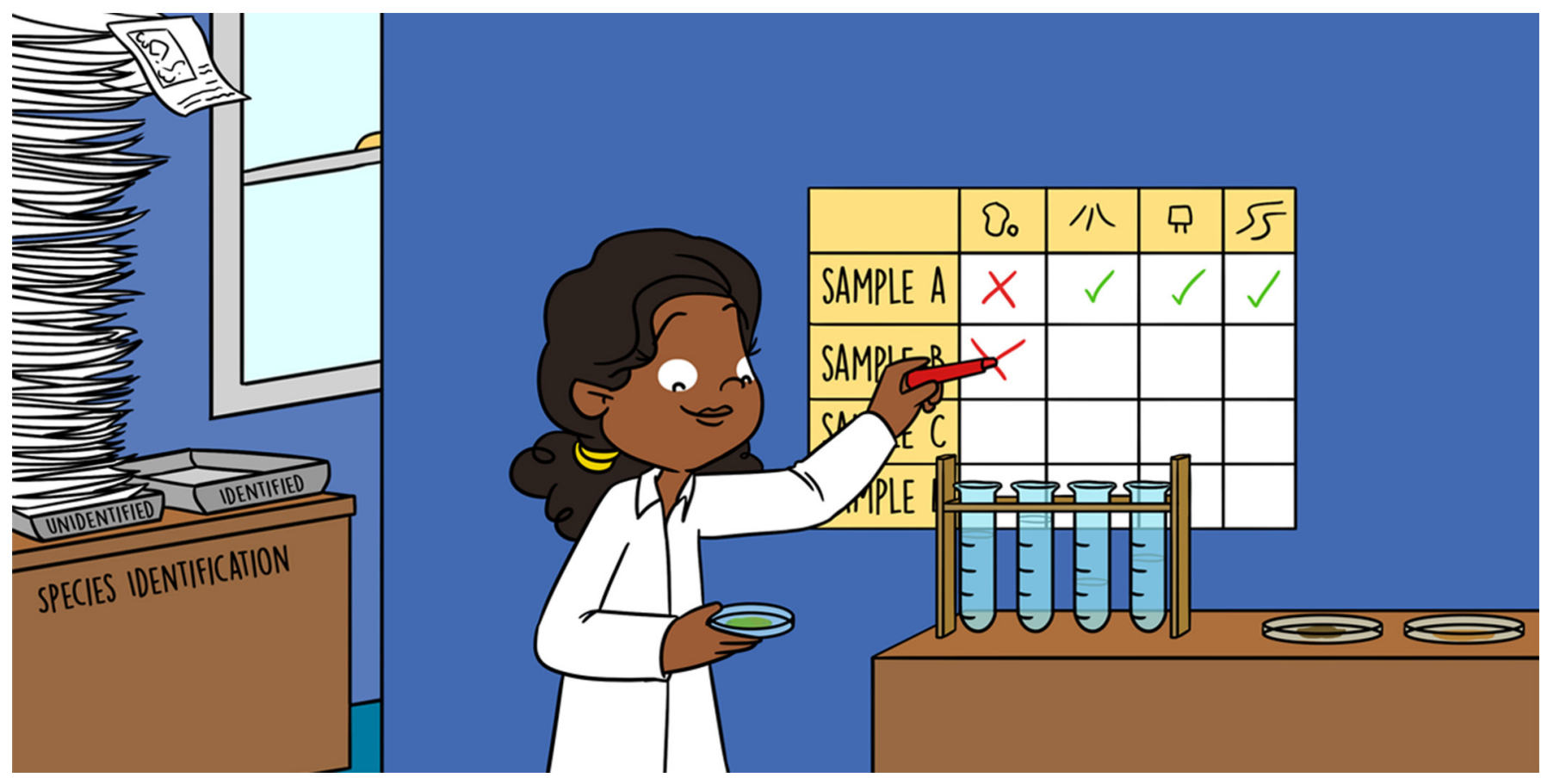

\title{
WHAT CAN DNA IN THE ENVIRONMENT TELL US ABOUT AN ECOSYSTEM?
}

\author{
Lena Schallenberg ${ }^{1}$, Susie A. Wood ${ }^{2}$, Xavier Pochon ${ }^{2,3}$ and John K. Pearman ${ }^{2 *}$ \\ ${ }^{1}$ Department of Zoology, University of Otago, Dunedin, New Zealand \\ ${ }^{2}$ Coastal and Freshwater Group, Cawthron Institute, Nelson, New Zealand \\ ${ }^{3}$ Institute of Marine Science, University of Auckland, Auckland, New Zealand
}

YOUNG REVIEWERS: MERCY SCHOOL

AGES: $14-15$
Scientists estimate that we share this planet with millions of other species! But how do we know which species are out there and how can we keep track of them? Unfortunately, humans are driving lots of species to extinction and disrupting important natural ecosystems. It is now more important than ever that we understand which species are present in different places and the roles they play in their ecosystems. With this knowledge, we can figure out how to protect important organisms and their habitats. Exciting new technology has made it possible to identify species using DNA that they have released into the environment-this is known as environmental DNA (eDNA). Scientists are now using eDNA to identify species in all kinds of ecosystems across the world. In this article, we explain how eDNA is used to detect species and describe the advantages and disadvantages of this method. 


\section{BIODIVERSITY}

The variety and variability among living organisms.

\section{INVASIVE SPECIES}

A species not normally found in an environment, which has the ability to spread quickly and take over from species normally found there.

\section{BASES}

Biological molecules which make up the twisted helix structure of DNA. Four molecules are used in the make-up of DNA: Adenine (A), Guanine (G), Cytosine (C), and Thymine (T).

\section{ENVIRONMENTAL}

\section{DNA (eDNA)}

Traces of DNA released by organisms into the environment. This DNA can come from scales, hair, skin, saliva, or waste products.

\section{MONITORING BIODIVERSITY IS IMPORTANT}

Humans are having an increasing impact on global biodiversity, which means our actions are reducing the total number of different species present on the planet. Many species are being driven to extinction before we even know anything about them or understand the roles they play in the environment. The loss of key species or the arrival of invasive species can change an ecosystem forever $[1,2]$. Because of this, studies of biodiversity are becoming increasingly important, so we can understand how various ecosystems are changing.

Traditionally, scientists have monitored ecosystems by physically exploring those locations, identifying the species living there based on how the organisms look, and counting the organisms [3]. This type of traditional monitoring requires the expert knowledge of scientists called taxonomists, who specialize in identifying species by closely analyzing them. Unfortunately, the number of scientists with these skills is declining, especially those who can identify rare species, which means that studies of biodiversity often are not as in-depth or as extensive as they should be.

As technology has improved, scientists have found another way to identify the species present in ecosystems-DNA. DNA basically contains the blueprint for every living organism, determining how each organism looks and functions. DNA is made up of two strands containing a combination of four chemicals called bases (cytosine [C], guanine [G], adenine [A], or thymine [T]) wound into a twisted, helical structure. Parts of the DNA sequence can act as "barcodes," which can help identify different species. This means that, by looking at a certain part of an organism's DNA, scientists can identify the organism.

\section{WHAT IS EDNA?}

Over the last 30 years, scientists have started using DNA barcodes to investigate which species are found in different environments. Substances found in the environment, such as water, soil, saliva, or faeces (poop) can contain DNA from the species living there. This DNA can come from the hair, scales, skin, saliva or waste products of the organisms in that environment. DNA collected from the environment is called environmental DNA (eDNA). Analysis of eDNA is rapidly changing the way scientists study ecosystems and biodiversity [4].

\section{HOW CAN EDNA BE USED TO IDENTIFY THE ORGANISMS IN A COMMUNITY?}

A community is made up of many different species. To identify the species making up a community in a certain ecosystem, samples 
Figure 1

How environmental DNA (eDNA) can be used to identify species. (A) Samples are collected from the environment (e.g., water, soil, feces).

(B) eDNA from organisms in each sample is extracted (removed) from the samples. (C) DNA sequences from the samples are multiplied through a method called PCR, so that there are enough sequences to study. (D) The sequences are then read on a sequencing machine, showing the order of bases on the DNA strands. (E) Sequences are then matched to known sequences in worldwide databases. (F) A list is produced of species found in that environment!

\section{POLYMERASE}

CHAIN REACTION (PCR)

A method by which many copies can be made of a piece of DNA, so that it can be sequenced and analyzed.

\section{DNA SEQUENCING}

The processing of finding out the sequence of bases along a strand of DNA.

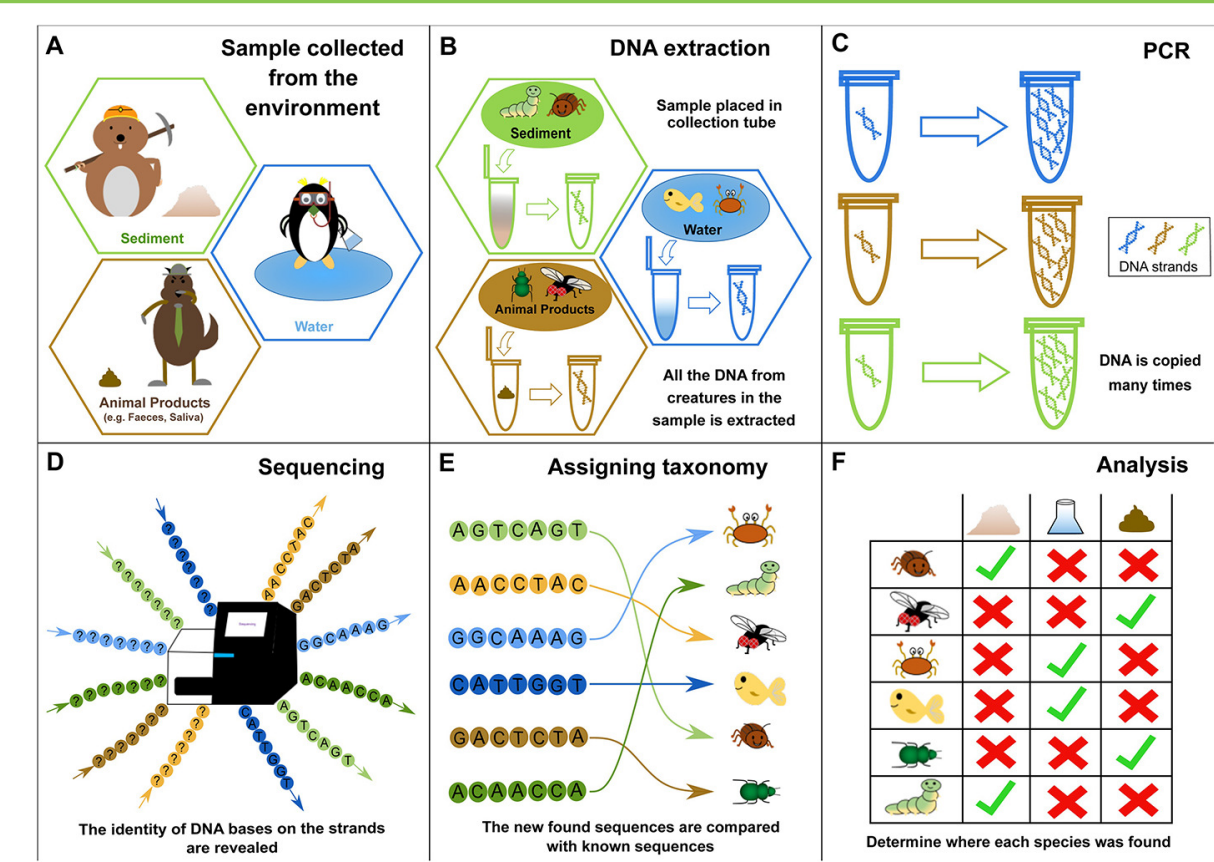

Figure 1

are taken from the environment and analyzed for eDNA. Specific short fragments of eDNA from the environment are multiplied using a process called polymerase chain reaction (PCR), so that there are enough of them to study. PCR makes thousands of copies of these DNA sequences from all the species in the sample. Since each species has a specific code made up of the four bases ( $A, C, G$, or T), these short sequences can act as identifiers for different species-much like a barcode identifies an item in a shop. DNA sequencing machines can read the order of these bases in the DNA. Once the barcode sequences are known, they can be matched with sequences in a database of known species. This way, the organisms present in the ecosystem can be identified (Figure 1).

\section{WHAT ARE THE ADVANTAGES OF USING EDNA TO IDENTIFY SPECIES?}

DNA-based methods have revolutionized the study of species that are hard to see and identify using traditional methods [5]. For example, most bacterial species look the same-like rods or spheres-making identification based on what they look like almost impossible. But scientists can tell these bacteria apart using eDNA. In fact, scientists did not even realize how many diverse species of bacteria there are until eDNA studies became common. Identifying species when they are young is often harder than when looking at their adult stage-think of frogs and tadpoles. Frogs of different species can look very different but often the tadpoles which they develop from look very similar. The ability to determine which species a juvenile belongs to is very 
CONSERVATION BIOLOGY

The protection and conservation of species and their habitats.

important for understanding the habitats that a species relies on for its different developmental stages. This knowledge can help scientists make the right decisions to help protect a species' habitat and preserve biodiversity. There are other reasons it is often difficult to detect species in the environment. Many species are good at hiding. Some can change the way they look in different environmental conditions, or they might live in habitats where they are difficult to see. For example, many invertebrates take shelter in coral reefs, and many species live in the dark depths of oceans or lakes. With the help of eDNA, the diversity present in many of the world's hidden ecosystems is being revealed.

Conservation biology is one field in which eDNA is being used. Conservation biology is the protection and conservation of species and their habitats. In this field, eDNA can both help to detect rare species and identify invasive species. Traditional monitoring to detect rare species is time consuming and often requires work in remote parts of the world, so eDNA provides an advantage. One interesting example of the use of eDNA comes from the study of rare vertebrates. Finding these rare animals is difficult, but eDNA can be obtained from the stomach contents of parasites like leeches and mosquitoes that feed on the rare animals, and these parasites are easier to find. eDNA can tell scientists which species the parasites have been feeding on, which can tell scientists if rare species are present in the area. eDNA can also be used as an early-warning system to identify invasive species as they spread into new environments. Because eDNA can detect species even when there are very few individuals in the environment, it can help us respond quickly to the threat of an invasive species. This means there is a greater chance of stopping the spread of an invasive species before it becomes established and potentially harms native species.

It is often less expensive to identify organisms using eDNA than it is to identify them using traditional methods [6], and eDNA samples can often be processed faster. This means that more samples can be taken over a wider range of space and time, allowing for in-depth studies and better knowledge of the species that are present in an ecosystem (Figure 2).

\section{ARE THERE ANY PROBLEMS WITH USING EDNA?}

Using eDNA to find species has helped us get a clearer picture of what is living on our planet, how many different species are living together, and how communities of organisms change over time. However, this technique still has three main limitations.

The first limitation of using eDNA to identify species is that, during the PCR reaction or the DNA sequencing process, sometimes mistakes can be made, preventing the DNA sequence from being copied or read properly. These errors could lead to a species being mis-identified. For 


\section{Figure 2}

Advantages of studying biodiversity using eDNA. Usine eDNA can reduce time and cost compared with traditional identification methods. This means that eDNA studies can be more in-depth and cover larger areas or longer time scales. eDNA can also be better at identifying hidden organisms or juveniles, which means more species can often be found than when using tradition methods.

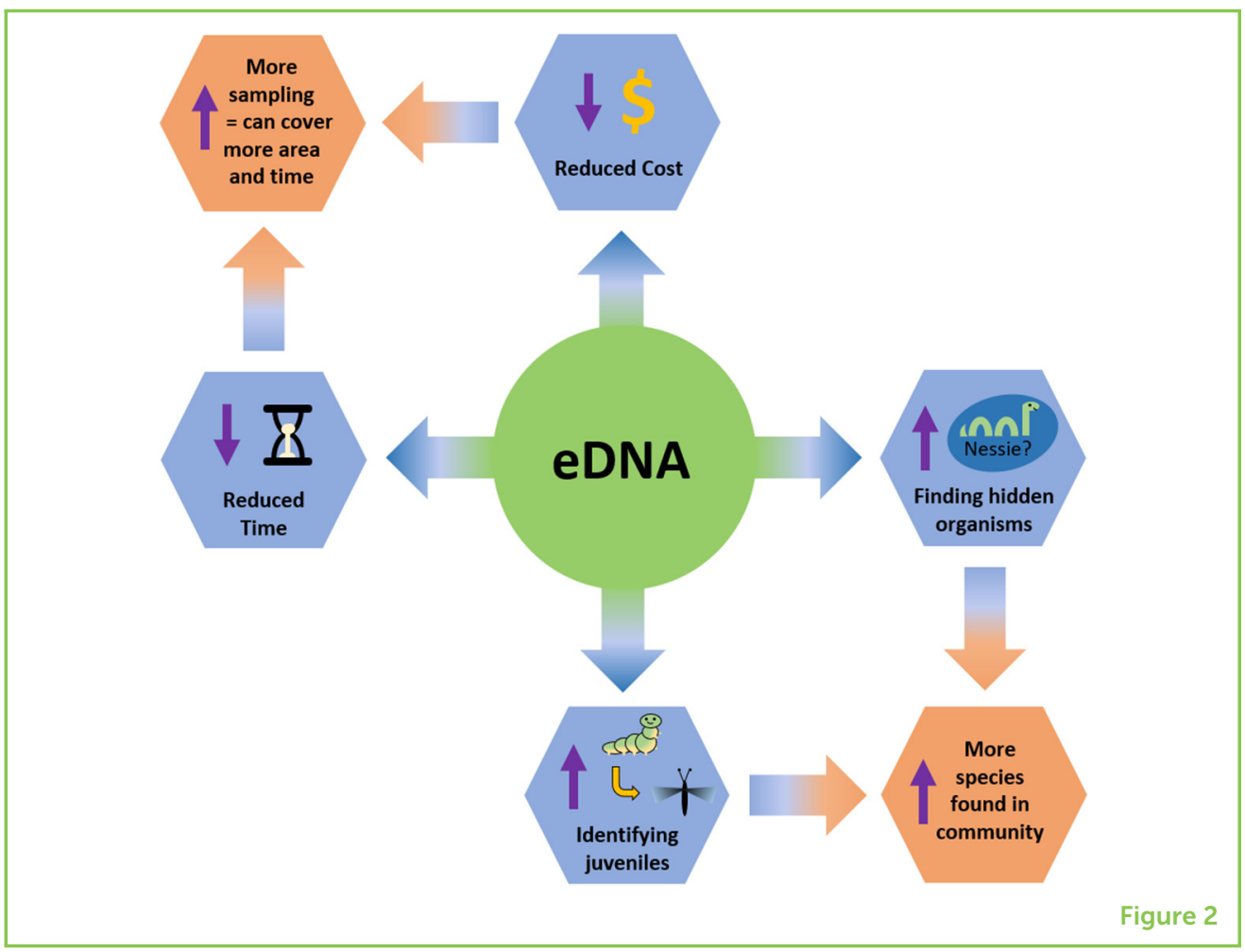

example, a species could either be missed when it is present (a false negative) or be identified as being present in a sample when it does not actually exist (a false positive).

Also, traditional methods of assessing biodiversity usually involve counting the number of organisms present in a sample, along with identifying which species are present. eDNA helps scientists know the number of different species found in a community. However, it does not tell them how many individual members of that species are present in that ecosystem, the way traditional counting would. Even if there is more DNA from a certain species, that does not necessarily mean there are more members of that species present. So, eDNA cannot be relied upon to give an accurate estimate of the number of organisms in a community.

One last potential limitation of using eDNA is that it might cause species to be identified incorrectly. To correctly identify an unknown species from a DNA sequence, the sequence is compared with a huge database containing barcodes of known organisms. This is done based on similarity-if the new sequence matches exactly with a known sequence, it is said to belong to that species. Unfortunately, the databases are incomplete because not all known species have been sequenced yet, so some sequences obtained from eDNA cannot be exactly matched to a known sequence. If the sequences do not exactly match an organism in the database, they are assigned to the closest matching sequence, which can sometimes be a quite different organism! 


\section{THE FUTURE OF eDNA}

Environmental DNA has helped reveal the enormous biodiversity existing on Earth. From studies of eDNA, the number of known organisms sharing our planet has increased substantially! eDNA methods are an incredible advancement in species detection, but there are still some issues that scientists need to work out. But, this field is progressing quickly and these techniques will become even more powerful and important in the future. So far, eDNA has given us a better picture of what species live on this Earth and the roles they play in their ecosystem, which means we can have a better idea of how to protect and conserve the world around us.

\section{ACKNOWLEDGMENTS}

The authors acknowledge the support of the New Zealand Ministry of Business, Innovation, and Employment research programmes-Our lakes' health; past, present, and future (C05X1707) \& A toolbox to underpin and enable tomorrow's marine biosecurity system New Zealand (CAWX1904)-as well as the University of Otago Ph.D. scholarship held by LS. We thank the reviewers, Science Mentor, and editor for their valuable and constructive comments. Finally we would also like to thank Susan Debad for making our manuscript more accessible to a young audience.

\section{REFERENCES}

1. Babić, I., Hudina, S., and Bielen, A. 2017. Invasion of the Chinese pond mussels - what makes these harmless-looking animals so dangerous? Front. Young Minds 5:56. doi: 10.3389/frym.2017.00056

2. Giovos, I., Katsanevakis, S., Coll, M., Piroddi, C., Steenbeek, J., Lasram, F. B. R., et al. 2019. Human activities help alien species to invade the Mediterranean sea. Front. Young Minds 7:97. doi: 10.3389/frym.2019.00097

3. Berkes, F., Colding, J., and Folke, C. 2000. Rediscovery of traditional ecological knowledge as adaptive management. Ecol. Appl. 10:1251-62. doi: $10.2307 / 2641280$

4. Taberlet, P., Bonin, A., Zinger, L., and Coissac, E. 2018. Environmental DNA: For Biodiversity Research and Monitoring. Oxford, UK: Oxford University Press.

5. Hebert, P. D. N., and Gregory, T. R. 2005. The promise of DNA barcoding for taxonomy. Syst. Biol. 54:852-9. doi: 10.1080/10635150500354886

6. Thomsen, P. F., and Willerslev, E. 2015. Environmental DNA-an emerging tool in conservation for monitoring past and present biodiversity. Biol. Conserv. 183:4-18. doi: 10.1016/j.biocon.2014.11.019

SUBMITTED: 04 August 2019; ACCEPTED: 11 December 2019; PUBLISHED ONLINE: 20 January 2020. 
EDITED BY: Pedro Morais, Centre of Marine Sciences, University of Algarve, Portugal

CITATION: Schallenberg L, Wood SA, Pochon X and Pearman JK (2020) What Can DNA in the Environment Tell Us About an Ecosystem? Front. Young Minds 7:150. doi: 10.3389/frym.2019.00150

CONFLICT OF INTEREST: The authors declare that the research was conducted in the absence of any commercial or financial relationships that could be construed as a potential conflict of interest.

COPYRIGHT (c) 2020 Schallenberg, Wood, Pochon and Pearman. This is an open-access article distributed under the terms of the Creative Commons Attribution License (CC BY). The use, distribution or reproduction in other forums is permitted, provided the original author(s) and the copyright owner(s) are credited and that the original publication in this journal is cited, in accordance with accepted academic practice. No use, distribution or reproduction is permitted which does not comply with these terms.

\section{YOUNG REVIEWERS}

\section{MERCY SCHOOL, AGES: 14-15}

We are an inventor class! We love to build and create in order to find solutions to real world problems. Our students come from all over the area to attend school.

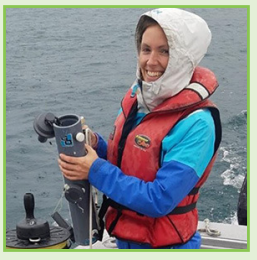

\section{AUTHORS}

\section{LENA SCHALLENBERG}

Lena delved into the world of eDNA while undertaking her Ph.D. at the University of Otago in New Zealand. She is looking at tiny picocyanobacteria that are important photosynthetic organisms in lakes. Because these bacteria are so small, they are super tricky to study and that is where eDNA comes in! This technique is helping her discover the many different types of picocyanobacteria, where they are living, and how they function. While conducting this study, she realized eDNA has some important limitations that biologists should be work to improve before this method can replace traditional techniques.

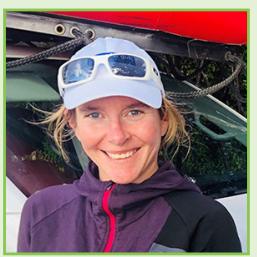

\section{SUSIE A. WOOD}

Susie is a biologist based at the Cawthron Institute in New Zealand. She is passionate about understanding and protecting aquatic environments. During her Ph.D., she explored the distribution and diversity of toxic cyanobacteria in New Zealand's lakes. Since completing this research, she has been particularity active in advocating for the incorporation of DNA-based tools in aquatic biomonitoring and biodiversity projects. She currently co-leads a large research project that, in combination with other techniques, uses eDNA to explore the current and historic biological communities in New Zealand's lakes (www.lakes380.com). 


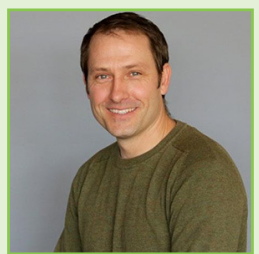

\section{XAVIER POCHON}

Of Swiss origin, it is against all odds that Xavier became a marine biologist with expertise in coral reef symbioses, ecology, and evolution. His passion for the ocean and contagious enthusiasm for marine discoveries have naturally led Xavier to conduct more than 20 years of successful research throughout the Indo-Pacific region. Established in New Zealand since 2012, Xavier now works at the Cawthron Institute and University of Auckland, promoting the use of high-throughput DNA and RNA sequencing for understanding human-induced biodiversity changes in aquatic ecosystems.

\section{JOHN K. PEARMAN}

John studied for his Ph.D. at the University of Warwick, UK and used DNA-based methods to explore small eukaryotic phytoplankton in the Atlantic Ocean. Subsequently, he moved to King Abduallah University of Science and Technology in Saudi Arabia, where he researched the diversity of the Red Sea using molecular techniques. Using these techniques, he studied organisms ranging from bacteria to macrofauna and from planktonic environments to coral reefs. More recently, he has joined the Cawthron Institute in New Zealand, to apply these molecular methodologies to investigating the past and present health of New Zealand's lakes (www.lakes380.com). *john.pearmanacawthron.org.nz 